ISSN: $1130-3743$

DOI: http://dx.doi.org/10.14201/teoredu2015271119136

\title{
EL MODELO EUROPEO DE PROTECCIÓN A LA INFANCIA EN INTERNET. DEL CUIDADO A LA RESPONSABILIDAD
}

\section{The European model for the on line protection of children. From the "media approach" to a "safer approach"}

\section{Le modèle européenne de protection à l'enfance sur Internet. Du soin à la responsabilité}

Juan García-GuTIÉRREZ

Universidad Nacional de Educación a Distancia. Facultad de Educación.

Departamento de Teoría de la Educación y Pedagogía Social.

C/ Juan del Rosal, 14. 28040 Madrid.juangarcia@edu.uned.es

Fecha de recepción: enero de 2015

Fecha de aceptación: abril de 2015

Biblid [(1130-3743) 27, 1-2015, 119-136]

\section{RESUMEN}

A lo largo de la historia, las jóvenes generaciones nunca como ahora habían tenido la posibilidad de acceder tan rápido a las innovaciones tecnológicas de su tiempo. Además, este acceso se produce sin apenas mediación por las generaciones adultas (padres, educadores, colegio, etc.). El ciberespacio y las tecnologías de la información y la comunicación se nos descubren como un ámbito especialmente sensible para la protección de colectivos vulnerables. Este trabajo trata de ofrecer un acercamiento hermenéutico a la doctrina jurídico-política elaborada por las instituciones comunitarias (principalmente por la Comisión) y un análisis filosófico-educativo 
de lo que hemos dado en llamar "modelo europeo para la protección a la infancia online", su especificidad y sus limitaciones en aras de avanzar hacia un enfoque más global e integrador y, por lo tanto, pedagógico.

Palabras clave: Protección online; responsabilidad online; seguridad online; derechos de la infancia; protección basada en contenidos; protección basada en la seguridad.

\section{SUMMARY}

Today, as never before, the youngest generations are being able to easily access the current technological innovations. Nevertheless, young people surf the Internet with no intervention from adult generations, namely their parents, educators, or school. Cyberspace and technologies of information and communication are considered a sensitive area where vulnerable groups, mainly children and teenagers, are in need of protection. This paper attempts to provide an hermeneutical approach to legal and political doctrine developed by the European institutions - namely the European Commission, as well as a philosophical and educational analysis of the so-called "European model for the on line protection of children", its specificity and limitations, in order to achieve a more comprehensive and integrated approach to the issue.

Key words: Online safer; online responsibility; online care; children rights.

\section{SOMMAIRE}

Tout au long de l'histoire, les jeunes générations n'ont jamais eu la possibilité d'acceder aussi rapidement aux innovations technologiques de leur temps comme aujourd'hui. En plus, cet accès se produit sans presque aucune médiation des générations adultes (c'est-à-dire des parents, des éducateurs, de l'école, etc.). Le cyberespace et les technologies de l'information et la communication s'avèrent comme un domaine particulièrement sensible pour la protection des groupes vulnérables. Cet article a comme objectif d'offrir une approche hermeneutique à la doctrine juridiquepolitique élaborée par les institutions européenes (notamment la Commision), ainsi qu'une analyse philosophique-éducative de ce que l'on appelle "le modèle européene pour la protection de l'enfance en ligne", son especificité et ses limitations au nom d'avancer vers une approche plus globale et intégratrice, et, par conséquence, plus pédagogique.

Mots clés: En ligne plus sûr; la responsabilité en ligne; les soins en ligne; droits de l'enfant. 
Donde está el peligro, allí surge también la salvación.

HÖLDERLIN

\section{INTRODUCCIÓN ${ }^{1}$}

En la historia de la humanidad, las jóvenes generaciones nunca habían tenido la posibilidad de acceder tan rápido a las innovaciones tecnológicas de su tiempo (de los móviles a Internet y redes sociales, del ordenador a las tablets). Incluso, sin apenas mediación por las generaciones adultas (padres, educadores, colegio, etc.). Es normal que esta precipitación genere disfunciones y problemas, a los que ya nos tienen habituados, por otra parte, los medios de comunicación en sus noticias.

Por otra parte, Internet y las tecnologías de la información y la comunicación (TIC) se han convertido también en un ámbito novedoso para la seguridad y la defensa. Tanto es así que las fuerzas de seguridad han sido de las primeras instituciones en ofrecer una respuesta a la cuestión de la protección y la seguridad; aunque, en algunos casos, no exenta de controversia (cfr. Fernández Guerra, 2014; Salamanca Aguado, 2014; Weiman, 2014). Recientemente, se reunían en Luxemburgo miembros de la Comisión y los ministros del Interior de los 28 con altos cargos de compañías de Internet (Facebook, Twitter, Google y Microsoft, etc.) ya que los responsables de la lucha antiterrorista habían llegado a la conclusión de que "no se puede combatir el yihadismo en Europa sin contar con la colaboración de las grandes compañías de Internet", ya que "no se trata sólo de aislar los mensajes negativos, sino de generar un discurso que disuada a los potenciales radicales de adentrarse en ese mundo" ${ }^{2}$.

Siendo para los jóvenes el ciberespacio un nuevo ámbito para su desarrollo, debemos procurar que sea un lugar seguro y adecuado, teniendo en cuenta que los niños, como proclamaba la Declaración de los derechos del niño (1958), gozarán de una protección especial y dispondrán de oportunidades y servicios para que puedan desarrollarse física, mental, moral, espiritual y socialmente en forma saludable y normal, así como en condiciones de libertad y dignidad (Principio II). Sin lugar a dudas, nos encontramos ante una temática importante y con un fuerte impacto en las políticas nacionales de los Estados. En España, por ejemplo, recientemente se ha aprobado la remisión a Cortes del Proyecto de Ley Orgánica de modificación del sistema de protección a la infancia y a la adolescencia ${ }^{3}$, y también

1. Este artículo forma parte del proyecto "Promoción del aprendizaje ético-cívico en Internet. Política, familia y escuela", desarrollado por el Grupo de Investigación El quehacer educativo como acción, financiado por el Plan Propio de Investigación, Desarrollo e Innovación de la Universidad Internacional de La Rioja - Unir Research.

2. "La uE insta a los gigantes de la Red a combatir el terrorismo online". El País, 7.10.2014.

3. Decisión del Consejo de Ministros de 20 de febrero de 2015. 
el Informe de la Subcomisión de estudio sobre las redes sociales, constituida en la Comisión de Interior del Congreso de los Diputados ${ }^{4}$.

En este sentido, una de las misiones que debe afrontar actualmente la Filosofía de la Educación, en línea con lo propuesto por Gil Cantero y Reyero García (2014), es introducir y elaborar categorías que faciliten el análisis y la (re)interpretación del sentido que tienen Internet y las tecnologías en el ámbito socioeducativo (Prats y Graell, 2015; García Aretio, 2014; García-Gutiérrez, 2013; Reyero García, García Aretio y Hernández Serrano, 2011; Burbules, 2001 y 2012; Fuentes, 2009). No sólo se trata de enseñar a usar los medios disponibles, sino, sobre todo, introducir y descubrir en ellos su intencionalidad y sentido pedagógico.

Este trabajo, por tanto, tiene como objetivo identificar, a través de un acercamiento hermenéutico a la doctrina jurídico-política elaborada por las instituciones comunitarias (principalmente, la Comisión), el modelo europeo de protección de la infancia online y analizarlo críticamente desde un enfoque filosófico-educativo. Esto nos llevará a detallar aquellas iniciativas jurídico-políticas que construyen el modelo; analizar críticamente los enfoques que lo articulan o caracterizan como un modelo en transición; y, también, por último, a señalar las limitaciones más importantes que impiden que lo educativo juegue un papel más activo y relevante en el desarrollo de este modelo de protección a nivel europeo.

\section{PRIMERAS MEDIDAS DE PROTECCIÓN A LA INFANCIA Y A LA JUVENTUd EN EL ÁMBiTO DE LOS MEDIOS AUDIOVISUALES}

La preocupación por la salvaguarda y protección de los menores en relación con los medios audiovisuales ha sido una constante comunitaria desde la década de los ochenta. En paralelo a los desarrollos en materia de liberalización y creación de un mercado común de las telecomunicaciones aparecían acciones relacionadas con la protección de consumidores y usuarios, especialmente niños y jóvenes ( $c f r$. Martínez Otero, 2012). En el Libro Verde sobre el establecimiento del mercado común de radiodifusión, especialmente por satélite y por cable (1984), base de la Directiva Televisión sin fronteras 5 , encontramos ya algunas claves de lo que serán los futuros desarrollos de la política sobre protección en relación a los medios, centrada en

4. Congreso de los Diputados. Bo Cortes Generales, n. ${ }^{\circ}$ 635, Serie D, de 24 de marzo de 2015, pp. 2-49.

5. «Los Estados miembros adoptarán las medidas oportunas para garantizar que sus emisiones de televisión no incluyan programas que puedan perjudicar seriamente el desarrollo físico, mental o moral de los menores y, en particular, programas que incluyan escenas de pornografía o violencia gratuita. Esta disposición se extenderá asimismo a los programas que puedan perjudicar el desarrollo físico, mental o moral de los menores, salvo que se garantice, por la elección de la hora de emisión o mediante toda clase de medidas técnicas, que dichos menores en el campo de difusión no ven ni escuchan normalmente dichas emisiones. Los Estados miembros velarán asimismo para que las emisiones no contengan ninguna incitación al odio por motivos de raza, sexo, religión o nacionalidad (art. 22)". 89/552/CEE de 3.10.1989. 
dos ámbitos: el terreno de las costumbres sexuales y la protección frente a escenas y representaciones de violencia (cfr. Moral Pérez, 1998).

El compromiso ético que desprende esta Directiva se traslada también a otros ámbitos como la publicidad, que no deberá perjudicar moral o físicamente a la infancia, ni aprovecharse de su inmadurez. Concretamente se fijan una serie de deberes, tales como: no atentar contra el respeto a la dignidad humana; no incluir elementos de discriminación por raza, sexo o nacionalidad; no atentar contra las convicciones religiosas o políticas; no fomentar comportamientos perjudiciales para la salud o para la seguridad; y no fomentar comportamientos perjudiciales para la protección del medio ambiente (art. 12).

El Libro Verde sobre la protección de los menores y de la dignidad humana en los servicios audiovisuales y de información ${ }^{6}$, de 1996, constituye un análisis amplio y global sobre la protección jurídica de los menores y la dignidad humana, contra la divulgación de contenidos ofensivos y perjudiciales para su desarrollo. El Libro Verde, además, sitúa la protección de la dignidad humana y de los menores como "bienes de gran interés público" (p. 1), tratando de equilibrar los derechos de libertad de expresión y de respeto a la vida privada con la protección de la infancia y la dignidad humana.

En el documento se identifican dos tipos de problemas con los contenidos. Por un lado, aquellos contenidos ilicitos, prohibidos en el conjunto de la sociedad (sea cual sea la edad de los potenciales destinatarios y sea cual sea el soporte) por considerarlos insoportables tanto para la persona como para el conjunto de la sociedad, ya que atentan contra los cimientos de la misma. Se prohíbe su producción, distribución, importación y publicidad. Se trata de "contenidos obscenos, contrarios a las buenas costumbres o indecentes", tales como la pornografía infantil; la pornografía violenta (incluida la pornografía que implica a adultos que no prestan su consentimiento) y la zoofilia (p. 15). También se encuentran aquellos contenidos que incitan al odio o a la violencia frente a personas o grupos de personas por razón de su raza, nacionalidad, color de piel, sexo o religión (p. 16).

Por otro lado estarían los contenidos nocivos, que, si bien son autorizados para adultos, se entiende que afectan al desarrollo físico o mental de los menores (p. 7). En el documento se citan varias formas de control, ya se trate de contenidos de radiodifusión o de contenidos online. Algunas modalidades son el control parental (codificando señal, por ejemplo); la protección basada en la franja horaria de difusión (sistema de horarios protegidos); o la clasificación de contenidos. Los medios online se centran en otras posibilidades como: bloqueo del ordenador, memorización de la navegación por las redes, filtrado de contenidos, etiquetado de contenidos, etc. (p. 23).

6. Libro Verde sobre la protección de los menores y de la dignidad humana en los nuevos servicios audiovisuales y de información. COM(96)483 final, de 16.10.1996. 
La Comunicación sobre contenidos ilegales e ilícitos en Internet ${ }^{7}$, de 1996, amplía el ámbito de protección a los contenidos online, afirmando el "principio de continuidad"; esto es, "aquello que es ilegal offline también lo es online (p. 4)". La Comisión muestra así su compromiso por garantizar el equilibrio entre la libre circulación de información y la protección del interés público en Internet (p. 4). Se analiza así el contexto técnico en el que puede actuarse para luchar contra los contenidos ilícitos y nocivos (p. 7), y se incluyen los contenidos fraudulentos y aquellos que supongan violación de los derechos de autor, difamación, invasión de la intimidad o publicidad comparativa ilegítima (p. 10). Un elemento importante es la inclusión del "margen de apreciación de los Estados" en la definición de los contenidos nocivos ${ }^{8}$.

Por último, en esta Comunicación se abordan temas específicos como el anonimato en la Red (p. 16) o los principios de localización jurídica (p. 17). Entre las medidas previstas son interesantes aquellas sobre autorregulación ( $c f r$. Muñoz Saldaña y Mora-Figueroa Monfort, 2007), los programas de control parental y filtrado (pp. 19 y ss.), pero sobre todo la creación de sistemas de valoración, como el "PEGI", que finalmente ha terminado imponiéndose en el ámbito de los videojuegos (Pérez Alonso-Geta, 2008); o la creación de mecanismos de denuncia, como las "líneas directas" (Sánchez Díez, Llorca Díez y Bueno Carrera, 2013).

Con la extensión de Internet en la década de los '90, y siguiendo la pista dejada por el Libro Verde y la Comunicación publicados en 1996, encontramos sendas Recomendaciones relativas a la protección efectiva de los menores y la dignidad humana en 1998 y en 2006, que avanzan el tema de la protección en contextos online, si bien, aún bajo el paradigma de la web 1.0.

La Recomendación de $1998^{9}$ aborda la necesidad de protección específica de la dignidad humana y los menores ante la expansión de las comunicaciones digitales, para favorecer un clima de confianza y credibilidad en la industria de servicios audiovisuales y de información online. La importancia de esta Recomendación estriba en la inclusión de un Anexo donde se recogen una serie de "Directrices indicativas para la aplicación, a escala nacional, de un marco de autorregulación

7. Comunicación de la Comisión al Consejo, al Parlamento Europeo, al Comité Económico y Social y al Comité de las Regiones sobre "Contenidos ilícitos y nocivos en Internet". COM(96)487 final, de 16.10.1996.

8. "Diversos tipos de materiales pueden constituir una ofensa a los valores o sentimientos de otras personas: contenidos que expresan opiniones políticas, creencias religiosas u opiniones sobre cuestiones raciales, etc. Lo que se considera nocivo depende de diferencias culturales. Cada país puede sacar sus propias conclusiones para la definición de la línea divisoria entre lo permisible y lo que no lo es. Por ello es imprescindible que las iniciativas internacionales tengan en cuentan las distintas normas éticas de los diversos países con el fin de sondear las normas adecuadas para la protección de la población frente a los materiales ofensivos, garantizando al mismo tiempo la libertad de expresión (p. 11)".

9. Recomendación del Consejo relativa al desarrollo de la competitividad de la industria europea de servicios audiovisuales y de información mediante la promoción de marcos nacionales destinados a lograr un nivel de protección comparable y efectivo de los menores y de la dignidad humana (98/560/ CE) de 24.9.1998. 
para la protección de los menores y de la dignidad humana en los servicios audiovisuales y de información en línea". Entre otras, la consulta y representatividad de las partes interesadas; los códigos de conducta; la creación de órganos nacionales que faciliten la cooperación a nivel comunitario ${ }^{10}$.

Por su parte, la Recomendación de $2006^{11}$ reitera algunas ideas ya publicadas sobre la necesaria protección del desarrollo físico, mental y moral de los menores en relación con los contenidos de los servicios audiovisuales y de información, y con la protección de los menores respecto del acceso a programas o servicios para adultos que son inapropiados ( $3 .{ }^{\text {er }}$ considerando). Sobre todo, acentúa la importancia de la alfabetización sobre medios que aparecen recogidas en el Anexo II. Éstas refuerzan el vínculo entre educación y protección, profundizando en las necesidades específicas de formación permanente de profesores y educadores; en la sensibilización sobre los riesgos de Internet entre los escolares; y en la formación específica sobre Internet y sobre su utilización responsable.

\section{3. \#BIK: LA Agenda Digital Europea desde los Derechos De los niÑos}

"\#BIK" es el hashtag creado por la Comisión para identificar su estrategia a favor de una Internet más adecuada para los niños (Better Internet 4 Kids). En esta estrategia confluyen dos preocupaciones de la Comisión. Por un lado, la referida al uso de las tecnologías en el territorio europeo; y, por otro, la relacionada con la salvaguarda y promoción específica de los derechos de la infancia. En este punto analizaremos esta Estrategia teniendo presentes tanto el marco general que diseña tanto la Agenda Digital Europa ${ }^{12}$, como la Agenda de la UE en pro de los Derechos del niño ${ }^{13}$.

La Agenda Digital para Europa (ADE) forma parte de la Estrategia de la uE (más conocida como "Estrategia Europa 2020" $\left.{ }^{14}\right)$ para regresar a la senda del crecimiento (inteligente, sostenible e integrador) durante la próxima década. Algo que implica mejorar el rendimiento de la UE en tres ámbitos interrelacionados: educación,

10. En el contexto español, puede verse el Código de autorregulación sobre contenidos televisivos e infancia. Consultado el 10 de enero de 2015. http://www.rpd.es/documentos/Codigo_y_criterios_ calificacion.pdf; y el sitio web: http://tvinfancia.es/ donde se encuentran los informes de seguimiento al Código de autorregulación.

11. Recomendación del Parlamento Europeo y el Consejo relativa a la protección de los menores y de la dignidad humana y al derecho de réplica en relación con la competitividad de la industria europea de servicios audiovisuales y de información en línea (2006/952/CE) de 20.12.2006. Además de estas Recomendaciones conviene prestar atención al informe de seguimiento, por cuanto supone una continuidad en las acciones comunitarias de protección de la infancia. Vid. Informe La protección de los niños en el mundo digital. COM(556) final, de 13.9.2011.

12. $\operatorname{COM}(2010) 245$ final, de 19.5.2010.

13. Una Agenda de la ue en pro de los Derechos del Niño. COM(2011) 60 final, 15.2.2001.

14. Europa: Una estrategia para un crecimiento inteligente, sostenible e integrado. $\operatorname{COM}(2010)$ 2020 final, de 3.3.2010. 
investigación e innovación. En la Agenda se insta a "obtener los beneficios económicos y sociales sostenibles que pueden derivar de un mercado único digital y a maximizar el potencial económico y social de las Tic para hacer negocios, trabajar, jugar, comunicarse y expresarse en libertad (p. 3)".

En general, la ADE trata de responder al "modo de vida digital» (p. 5) adoptado por muchos europeos para aprovechar al máximo todo el potencial económico. De los campos de acción señalados, aquellos que inciden directamente en nuestra labor de análisis son los relacionados con la creación de confianza y seguridad en el mundo digital; fomentar la alfabetización, la capacitación y la inclusión digitales, señalando como fundamental: la alfabetización y capacitación digitales; y servicios digitales incluyentes (pp. 8-30), con el objetivo de mejorar la capacitación digital para la innovación y el crecimiento (p. 29).

Por su parte, la Agenda sobre los derechos del niño (que también se enmarca en la "Estrategia Europa 2020") tiene como fin específico el respeto y la promoción del interés superior del niño en todas las políticas desarrolladas por la UE que afecten a la infancia (p. 4). Concretamente, adaptar la justicia a los niños (ya se trate de víctimas, testigos, personas sospechosas, solicitantes de asilo, etc.); proteger a los niños más vulnerables (este punto es especialmente relevante, por cuanto se hace mención expresa a, entre otros, los "niños internautas" por cuanto pueden exponerse a contenidos inadecuados o ser víctimas de ciberacoso); promover y proteger los derechos del niño en la acción exterior de la UE; y, por último, establecer acciones de sensibilización respecto a sus propios derechos y a la participación en las decisiones que les afectan.

La consideración de los niños y jóvenes (menores, en general) como población "especialmente vulnerable" frente a las nuevas tecnologías (p. 12) es fundamental. La vulnerabilidad aparece cuando se accede a determinados contenidos y conductas ilícitas (como ciberacoso y/o manipulación). Se trata de conductas que también se producen offline ("principio de continuidad"). Desde esta perspectiva, la Comisión subraya la necesidad de alcanzar un alto nivel de protección de los niños en el ciberespacio (p. 12), abarcando tanto sus datos personales, como el "derecho de acceso" para facilitar su desarrollo social y cultural. Sin embargo, cuenta con una limitación importante, ya que al centrarse en los derechos y su protección no aborda suficientemente el ámbito de los menores infractores online.

Curiosamente, la justificación que aparece en el Preámbulo de la Estrategia europea a favor de una Internet más adecuada para los niños ${ }^{15}$ se aleja de estas consideraciones jurídicas y se vincula a la cuestión económica. En efecto, la iniciativa se justifica por cuanto se trata de «nuevas oportunidades para los niños y para el desarrollo empresarial",

15. Estrategia europea a favor de una Internet más adecuada para los niños. COM(2012) 196 final, de 2.5.2012. 
aun cuando la Agenda digital para Europa se propone familiarizar a todos los europeos con el mundo digital, las necesidades particulares y los puntos vulnerables de los menores en Internet merecen un tratamiento específico que permita que esta se convierta en un lugar en el que los niños puedan acceder al conocimiento, comunicarse, desarrollar sus aptitudes y mejorar sus perspectivas laborales y su empleabilidad (p. 1).

Reconoce que "prestar atención a las demandas de los niños abre un amplio abanico de oportunidades para las empresas (p. 3)", y termina afirmando que "los propios niños podrían convertirse en creadores en línea e iniciar una actividad empresarial (p. 3)". En esta misma línea y sobre el "fracaso del mercado a la hora de ofrecer medidas de protección y contenidos de calidad en Europa" se afirma que "todavía no se ha cobrado conciencia de que los niños constituyen una audiencia en la que merece la pena invertir (p. 4)". Estas afirmaciones refuerzan el enfoque económico de las Tic, en detrimento de una visión más pedagógica para la promoción de la autonomía y de los derechos de la infancia en el ciberespacio.

En la Estrategia se identifican además dos ámbitos. Uno que trata de justificar el sentido y la necesidad de la propia Estrategia, apelando a las razones económicas ya señaladas; y otro, en el que se describen las principales acciones o medidas a emprender (la industria, los Estados y la propia Comisión) para lograr un ambiente online seguro. Este "nuevo ecosistema", tal y como lo define la propia Estrategia, se asienta sobre cuatro pilares (pp. 7 y ss.). En primer lugar, unos contenidos en línea de alta calidad para niños y jóvenes. En segundo lugar, intensificar la sensibilización y la capacitación. Conociendo los riesgos pero también cómo protegerse de ellos mediante la enseñanza de la seguridad en la escuela; desarrollando el pensamiento crítico y sus aptitudes de alfabetización digital y mediática; y también, intensificando las actividades de sensibilización y participación de los jóvenes e implementando herramientas de denuncias para los usuarios. En tercer lugar, la creación de un entorno en línea seguro para los menores, concretado en algunas medidas tales como los parámetros de confidencialidad en relación a la privacidad de los menores; el uso del control parental; o los sistemas de clasificación por edades y por contenidos. Por último, la Estrategia aborda el tema de lucha contra los abusos sexuales y la explotación sexual de los niños.

No podemos terminar este apartado sin citar otras acciones Comunitarias relevantes en este ámbito, y que sin duda también definen del modelo europeo de protección a la infancia online. Se trata del desarrollo del plan plurianual Safer Internet (1999/2004), y su continuación, el Safer Internet Plus (2005/08) ${ }^{16}$. Desde su

16. Decisión por la que se aprueba un plan plurianual de acción comunitaria para propiciar una mayor seguridad en la utilización de Internet mediante la lucha contra los contenidos ilícitos y nocivos en las redes mundiales (276/1999/CE, de 25.1.1999); Decisión 1151/2003/CE de 16.6.2003, por la que se prorroga la Decisión 276/1999/CE, de 25.1.1999; Decisión por la que se crea un programa comunitario plurianual para el fomento de un uso más seguro de Internet y las nuevas tecnologías en línea $(854 / 2005 / \mathrm{CE}$, de 11.5.2005). 
creación, estos programas han tenido como objeto actuar tanto en el ámbito de los contenidos, como en el de los comportamientos nocivos e ilícitos contra los niños. Además, también se han desarrollado dos iniciativas importantes como son el "Día de Internet seguro"; y la creación del "Foro Internet Segura" (desde 2004). Junto a las sucesivas evaluaciones que han tenido estos Programas ${ }^{17}$, también han sido importantes los Informes elaborados por las redes europeas insafe e inhope ${ }^{18}$. Por último, también ha sido especialmente fructífera la cooperación con la industria, por ejemplo, en la firma de los Principios para unas redes sociales más seguras ${ }^{19}$.

Junto a las iniciativas anteriores, vinculadas al sector digital, es necesario tener presentes otros "documentos e iniciativas conexas" que completan el discurso europeo sobre protección de la infancia online y que se centran en el sector educativo.

En efecto, también para la educación el punto de partida está en las acciones incluidas en el pilar 6 de la ADE, sobre el fomento de la alfabetización, la capacitación y la inclusión digitales (pp. 28 y ss.). En esta dirección se orienta la iniciativa Un nuevo concepto de educación (Rethinking Education) ${ }^{20}$ donde se subraya la importancia de la formación en competencias transversales y básicas, sobre todo la competencia digital ${ }^{21}$. Desde la primera frase no caben dudas sobre su intención (y la relación esperada entre: competencias digitales, educación y empleo), "la inversión en educación y formación, a fin de desarrollar las aptitudes de los

17. Evaluación del plan plurianual de acción comunitaria para propiciar una mayor seguridad en la utilización de Internet y las nuevas tecnologías en línea mediante la lucha contra los contenidos ilícitos y nocivos, principalmente en el ámbito de la protección de los niños y los menores. com (2003) 653 final, de 3.11.2003; y la Evaluación final de la ejecución del programa comunitario plurianual para el fomento de un uso más seguro de Internet y las nuevas tecnologías en línea. com (2009) 64 de 18.2.2009.

18. Consultado el 10 de enero de 2015. http://www.saferinternet.org; http://www.inhope. org. También: Insafe-inhope Annual Report working together for a better Internet for children and Young people. Consultado el 10 de enero de 2015. http://www.saferinternet.org/c/document_library/ get_file?uuid=0f285af4-8fff-489d-8da8-2298a8ed898d\&groupId=10137.

19. Principios de la ue para unas Redes Sociales más Seguras (IP/09/232). En ellos se recogen una serie de medidas tales como: proporcionar un botón de "denuncia de abusos" fácil de utilizar y accesible; asegurarse de que todos los perfiles y listas de contactos en línea de los usuarios de los sitios web registrados como menores de 18 años estén predeterminados como "privados"; asegurarse de que los perfiles privados de los usuarios menores de 18 años no puedan buscarse. Garantizar que las opciones de privacidad estén destacadas y sean accesibles en todo momento; impedir que los menores de edad utilicen sus servicios: si una red social está dirigida a adolescentes de más de 13 años, a los menores de esa edad debe resultarles difícil registrarse.

20. $\operatorname{COM}(2012) 371$ final, de 20.11.2012.

21. Cfr. Measuring Digital Skills across the EU: EU wide indicators of Digital Competence. Consultado el 10 de enero de 2015. http://ec.europa.eu/information_society/newsroom/cf/dae/document. cfm?doc_id=5406. También son interesantes los siguientes informes: el Survey of Schools: ICT in Education. Benchmarking Access, use and attitudes to technology in Europe's schools. Consultado el 10 de enero de 2015. https://ec.europa.eu/digital-agenda/sites/digital-agenda/files/KK-31-13-401-EN-N.pdf y el Informe Digital Competences in the Digital Agenda. Consultado el 10 de enero de 2015. https:// ec.europa.eu/digital-agenda/sites/digital-agenda/files/scoreboard_digital_skills.pdf. 
ciudadanos, es fundamental para impulsar el crecimiento y la competitividad: las aptitudes son determinantes para que Europa sea capaz de potenciar su productividad ${ }^{22}$.

También es importante destacar las llamadas "cibercapacidades". Ya en 2007 la Comisión presentó la Comunicación sobre Cibercapacidades para el siglo Xxi ${ }^{23}$, donde expresaba su preocupación por la falta de formación para empleos vinculados a las $\operatorname{TIC}^{24}$. En efecto,

La capacidad de las empresas europeas de competir y evolucionar a principios del siglo xxi depende cada vez más del uso innovador y efectivo de las nuevas tecnologías de la información y la comunicación (TIC). La estrategia de las cibercapacidades es un componente de la Agenda Digital para Europa y el Paquete de Empleo para estimular la competitividad, productividad y empleabilidad de la mano de obra ${ }^{25}$.

Por último, en 2013 la Comisión lanzó la iniciativa "Educación abierta»" Quizá la propuesta más relevante en el ámbito educativo relacionada con las Tic, destinada a cambiar la visión tradicional de la educación en la UE desde la oportunidad que ofrece la tecnología y los recursos educativos en abierto (REA). Siempre sin perder de vista la competitividad económica ${ }^{27}$.

22. Y continúa el texto: "Los sistemas europeos de educación y formación siguen teniendo carencias a la hora de aportar una preparación que contribuya a la empleabilidad, y no trabajan debidamente con las empresas o los empleadores para aproximar la experiencia del aprendizaje a la realidad del entorno laboral (p. 2)". $\operatorname{Com}(2012) 371$ final, de 20.11.2012.

23. Comunicación sobre Cibercapacidades para el siglo xxi: fomento de la competitividad, el crecimiento y el empleo. $\operatorname{com}(2007) 496$ final, de 7.9.2007. Este documento es fruto de los resultados del Consejo de 2002 y de la presidencia danesa que auspiciaron una Cumbre sobre Cibercapacidades de 2002 para promover la competitividad, la empleabilidad y el desarrollo de la mano de obra.

24. Más recientemente, se ha mostrado que aquellos países con un mayor dominio de las cibercapacidades también tenían una puntuación más elevada en los índices de innovación y competitividad (como el Índice de Conectividad, que mide las capacidades de las economías para hacer uso de las TIC para incrementar su competitividad y desarrollo). KORTE, B. W.; GAREIS, K. y HüsING, T. (2014) Cibercapacidades para trabajos en Europa. Midiendo el progreso y avanzando. Comisión Europea. Consultado el 10 de enero de 2015. http://eskills-monitor2013.eu/fileadmin/monitor2013/documents/ Country_Reports/Brochure/eSkills_Monitor_ES.pdf (consultado el 2.2.2015).

25. KORTE, B. W.; Gareis, K. y Hüsing, T. (2014) Cibercapacidades para trabajos en Europa. Midiendo el progreso y avanzando. Comisión Europea..., 3.

26. "Educación abierta" propone acciones encaminadas a lograr unos entornos de aprendizaje más abiertos, que proporcionen una educación de mayor calidad y eficacia y que contribuyan a los objetivos de Europa 2020 de impulsar la competitividad y el crecimiento de la uE a través de una mano de obra más cualificada y más empleo. Apertura de la educación: docencia y aprendizaje innovadores para todos a través de nuevas tecnologías y recursos educativos abiertos. сом(2013) 654 final, de 25.9.2013.

27. También es importante mencionar otros documentos, como Informe técnico sobre competencias digitales (e-competencias) en la práctica; Análisis y marcos de referencia del Joint Research Centre (2012); o la Agenda nuevas competencias para nuevos trabajos. En todos ellos se pone de manifiesto la importancia de la inclusión de la tecnología en el sector educativo, y la mejora de las competencias digitales para incrementar la productividad y favorecer una economía más dinámica. 


\section{El modelo EUROPEO De PROTECCIÓN A LA infancia ONLINE. UN MODELO EN TRANSICIÓN}

\subsection{Del media approach al safety approach}

Desde los años ochenta del pasado siglo, la Unión Europea ha estableciendo medidas para luchar contra contenidos ilícitos y nocivos para la infancia y la juventud y que atentan también contra la dignidad humana. En las primeras medidas de la Comisión observábamos la centralidad que tenía el cuidado y la preocupación por los contenidos en la protección. Sin embargo, con el paso del tiempo, paulatinamente, este marco se ha ampliado. Así, se puede diferenciar entre una protección orientada a los contenidos (que hemos llamado media approach), vinculada con los medios audiovisuales tradicionales, y un tipo de protección orientado a las interacciones (safety approach) propio de la web social y el uso de las Tic. De tal forma, que a la preocupación por los contenidos se le suma también la preocupación por lo que los niños y jóvenes hacen en Internet y con las tecnologías. Es una perspectiva que tiene en cuenta los riesgos pero también las posibilidades que ofrece el ciberespacio.

El llamado media approach resulta de la combinación de varios elementos. En primer lugar, una "lógica editorial", ya que son los propios medios quienes producen y/o difunden contenidos en diversos formatos audiovisuales para ser consumidos de manera (cuasi)individual. Por tanto, la responsabilidad de proteger reside en ellos mismos. En segundo lugar, encontramos una estructura comunicativa lineal (emisor-receptor) que facilita el control del contenido (mensaje). El control admite así una gradación diversa, en función del interés o intención que se tenga. Desde la falta de control y la desregulación más absoluta al control férreo sobre los contenidos, como sucede en la censura. Además el control sobre los contenidos se puede ejercer de manera interna a los medios (autorregulación), o bien externa (a través de consejos reguladores ${ }^{28}$, por ejemplo).

La aparición de Internet (web social o 2.0) ha supuesto una evolución del modelo de protección mediática tradicional orientada a los contenidos. Como han puesto de manifiesto numerosos estudios sobre seguridad e infancia online (InsafeInhope, 2015; Mascheroni y Cuman, 2014; Livingstone et al., 2014; Livingston, Haddon et al., 2011) los principales peligros ya no se encuentran sólo en el acceso a contenidos ilícitos o nocivos, sino también en el tipo de conductas y relaciones sociales que se desarrollan online en el ciberespacio (del ciberacoso o el sexting a las adicciones tecnológicas ${ }^{29}$, por ejemplo). Internet y las herramientas y aplicaciones de la web social han roto la lógica de la edición y la estructura comunicativa

28. Podemos citar, por ejemplo, la Ley 7/2010, de 31 de marzo, General de la Comunicación Audiovisual que prevé la formación de un Consejo Estatal de Medios Audiovisuales (como autoridad independiente supervisora y reguladora de actividad de los medios art. 45), y donde se reconocen también unos derechos al público, y específicamente a los menores (art. 7).

29. Cfr. Caro Samada, Ariso y Plaza, 2014. 
lineal de los medios tradicionales, haciendo que el cuidado y el control sobre los contenidos se desborde, haciéndolo casi imposible en sociedades democráticas ${ }^{30}$. Además, en el caso del media approach, al poner el foco en los contenidos, la responsabilidad queda diluida en el mundo de los adultos (sistemas de control parental, autorregulación, etc.) alejándola de los usuarios, un modelo de protección inviable en el mundo online.

\section{Cuadro 1. Características del MOdelo EuRopeo de Protección A LA INFANCIA ONLINE. UN MODELO EN TRANSICIÓN}

\begin{tabular}{ccc}
\hline & $\begin{array}{c}\text { Modelo basado en contenidos } \\
\text { (media approach) }\end{array}$ & $\begin{array}{c}\text { Modelo basado en } \\
\text { la interacción } \\
\text { (safety approach) }\end{array}$ \\
\hline $\begin{array}{c}\text { Lógica de la edición } \\
\text { Orientación }\end{array}$ & Web 1.0 & Web 2.0 \\
\hline $\begin{array}{c}\text { Tipo de protección } \\
\text { Medidas de } \\
\text { protección }\end{array}$ & Contenidos & Relaciones \\
\hline Tipo de narrativa & $\begin{array}{c}\text { Autorregulación } \\
\text { Control paterno }\end{array}$ & $\begin{array}{c}\text { Basada en la seguridad/ } \\
\text { responsabilidad }\end{array}$ \\
\hline $\begin{array}{c}\text { Actitudes que } \\
\text { promueven }\end{array}$ & Lineal & Alfabetización mediática \\
\hline Imagen de la infancia & Niño espectador/consumidor & Niño usuario/creador online \\
\hline
\end{tabular}

FUENTE: Elaboración propia.

El cuadro resume los principales elementos de análisis que es necesario tener en cuenta para examinar los discursos políticos y jurídicos que orientan y también construyen el modelo europeo de protección a la infancia. El modelo europeo,

30. Si bien, en algunos países la censura en la Red no es sólo posible, sino que crece. Cfr. FreEdom House (2014). Freedom on the net "Tightening the Net: Governments Expand Online Controls". Consultado el 16 de abril de 2015. https://freedomhouse.org/sites/default/files/FOTN_2014_ Full_Report_compressedv2_0.pdf. Además en las sociedades democráticas crece el debate y la tensión entre la libertad de expresión y la protección a la infancia, por ejemplo, en el caso de los desnudos en la Red o en relación con la actividad de grupos radicales en las redes sociales. Vid. "Estas son las imágenes que Facebook no quiso que vieras". Consultado el 16 de abril de 2015; "¿Debe Facebook censurar esta foto?». Consultado el 16 de abril de 2015 http://verne.elpais.com/verne/2015/03/11/articulo/1426096766_908610.html; "Facebook detalla las normas de su censura”. Consultado el 16 de abril de 2015 http://www.lavanguardia.com/tecnologia/redes-sociales/facebook/20150316/54429025219/ facebook-detalla-normas-censura.html. 
como vemos, partiendo de posiciones basadas en el cuidado de la infancia en relación a los contenidos, se ha ido desplazando hasta abrirse a las interacciones y conductas desarrolladas online. De ahí que podemos hablar de un modelo en transición. Igualmente, no se trata tampoco de modelos antagónicos sino de un modelo de protección en transición que evoluciona según las exigencias y novedades tecnológicas del momento.

Estos elementos determinan el tipo de protección y la orientación de las medidas previstas en los programas europeos. Mientras la orientación a contenidos se basa en el cuidado y desarrolla una protección pasiva (para la infancia) como las medidas de autorregulación o el control parental; el modelo basado en las relaciones se orienta a la protección de la confianza y la seguridad online desde la responsabilidad de los propios usuarios, incluidos los menores. De ahí el acento en un tipo de medidas más educativas como la alfabetización mediática o el desarrollo de la competencia mediática y/o digital. En este modelo las medidas educativas promueven la responsabilidad de los propios niños y jóvenes, como usuarios y creadores en el ciberespacio. Sin embargo, esta orientación educativa del modelo se limita al chocar con la filosofía económico-productiva que, desde la "estrategia de Lisboa", impregna todas las medidas comunitarias.

Por otra parte, también es diferente la forma en que se construye socialmente la imagen de infancia en ambos modelos. Es necesario tener en cuenta el tipo de narrativa desde la que los niños y jóvenes construyen sus horizontes de sentido, su identidad y sus vínculos de pertenencia ( $c f r$. Ramiro Vázquez, 2013). La narrativa que configura la identidad en los jóvenes ha dejado de ser lineal para asumir una estructura hipertextual o incluso transmedia. La estructura narrativa de la personalidad se impregna también de los nuevos modelos comunicativos con los que crecen los jóvenes. Además, no podemos olvidar las actitudes y valores que promueven. Mientras los "medios 1.0" acentúan el papel de consumidores y espectadores, el modelo basado en las interacciones reconoce el papel activo y creador de los niños y jóvenes; abriendo así las posibilidades de intervención educativa para el desarrollo de la responsabilidad y la autonomía en el ciberespacio.

Sin abandonar el estatus de vulnerabilidad que tienen niños y jóvenes, según la evolución de sus facultades, el modelo media approach acentúa una imagen pasiva e inmadura de la infancia, suponiendo así un menor aprovechamiento de Internet y las tecnologías por niños y jóvenes, algo del todo desmentido por la realidad. Pedagógicamente, el cuidado es necesario pero no suficiente; y no podemos esperar que el pleno desarrollo de la personalidad en el ciberespacio se produzca sólo atendiendo a los peligros y riesgos, sin avanzar en las posibilidades sociales y culturales que ofrecen Internet y las tecnologías para el desarrollo de experiencias positivas en los ámbitos ético y cívico. 


\subsection{Limites en el desarrollo del modelo de protección a la infancia online basado en la responsabilidad}

Ahora bien, en ocasiones, esta comprensión pedagógica de la protección a la infancia choca con algunos límites y reduccionismos que aparecen en los discursos sobre protección de la infancia online. Como ya hemos apuntado, el reduccionismo económico de la competencia digital, y también el reduccionismo con el que se concibe la propia noción de confianza.

La competencia digital aparece descrita en el texto sobre Competencias clave y aprendizaje permanente ${ }^{31}$ como aquella que,

entraña el uso seguro y crítico de las tecnologías de la sociedad de la información (TSI) para el trabajo, el ocio y la comunicación. Se sustenta en las competencias básicas en materia de Tic: el uso de ordenadores para obtener, evaluar, almacenar, producir, presentar e intercambiar información, y comunicarse y participar en redes de colaboración a través de Internet (p. 7).

En esta definición se integran la noción de seguridad y de capacidad crítica. Ahora bien, como se observa, las iniciativas comunitarias se han centrado en el primero de los términos del binomio; esto es, el "uso seguro". En el ámbito educativoescolar, esta competencia se ha vinculado más a la esfera del uso: competencia, empleabilidad y productividad, y no tanto en el desarrollo de la dimensión crítica que se le presupone ${ }^{32}$. Igualmente sobre la noción de confianza opera esta preeminencia económica (market based approach), que la aleja de su función y carácter ético y social y la impone por su valor económico. Estas dos formas de reduccionismo comprometen el desarrollo de la competencia digital, menoscabando su sentido y alcance.

Si bien todos acordamos (formalmente) que el pleno desarrollo de la personalidad es el fin de la educación, la realidad nos muestra, a las claras, que ese desarrollo se reduce a la dimensión puramente profesional y laboral. Este reduccionismo se refleja en algunas ideas presentes en la Estrategia europea a favor de una Internet más adecuada para los niños: "prestar atención a las demandas de los niños abre un amplio abanico de oportunidades para las empresas (p. 3)»; "todavía no se ha cobrado conciencia de que los niños constituyen una audiencia en la que merece la pena invertir (p. 4)". Por su parte, la confianza también ha visto disminuidas sus posibilidades pedagógicas, al quedar reducida al contexto de la

31. "Competencias clave para el aprendizaje permanente. Un marco de referencia europeo", es el Anexo de la Recomendación del Parlamento Europeo y del Consejo, de 18 de diciembre de 2006, sobre "Las competencias clave para el aprendizaje permanente". Do L 394, de 30 de diciembre de 2006.

32. Como se pone de manifiesto en el Informe Students in the digital age. Current State of Play, sólo un $2 \%$ de los estudiantes mantiene un pensamiento crítico mientras busca información. Consultado el 10 de enero de 2015 .

http://www.iea.nl/fileadmin/user_upload/Studies/ICILS_2013/ICILS_2013_infographic.pdf en este aspecto puede verse también el trabajo de: Fraillon, et al. (2014). 
seguridad, como garante para las transacciones comerciales ${ }^{33}$. Tratándose de dos acciones radicalmente diferentes, este tipo de reduccionismo económico lleva a identificar ciudadanía y consumo.

Por tanto, el modelo europeo de protección a la infancia online no puede configurarse únicamente atendiendo a los peligros y riesgos que las tecnologías e Internet suponen para el desarrollo de niños y jóvenes. Ya se trate de contenidos nocivos o ilegales o de conductas de riesgo como las adictivas o las antisociales, es necesario construir un enfoque global e integrador, donde la perspectiva de los derechos del niño se enriquece por un enfoque pedagógico de la tecnología, en aras de optimizarla para lograr el pleno desarrollo de la personalidad. Igualmente, es necesario que las políticas comunitarias sean capaces de trascender el enfoque puramente económico instalado actualmente en Bruselas.

Esta transición en el modelo de europeo de protección se caracteriza, justamente, por aprovechar también las posibilidades educativas de las tecnologías online para el desarrollo de la identidad y de valores cívicos en el ciberespacio. Se trata, por tanto, de avanzar hacia un modelo basado en la responsabilidad, que apela directamente a la libertad y, por tanto, nos obliga a comprender el ciberespacio no como algo neutral sino radicalmente ético.

En conclusión, podemos afirmar que el modelo europeo de protección a la infancia descansa sobre tres pilares. Uno de naturaleza propiamente jurídica, vinculado al respeto y promoción de los derechos humanos y, particularmente, de los derechos de los niños; otro de índole política, promoviendo la cooperación intergubernamental y el desarrollo de programas comunitarios para la protección de la infancia; por último, un tercer pilar estrictamente educativo, que concreta los dos anteriores y se centra en el desarrollo holístico de la seguridad online desde una triple perspectiva: la protección, la prevención y la promoción. Además, este modelo deberá trascender los planteamientos puramente económicos si de verdad pretende afirmar, sin lugar a dudas, el interés superior del niño en el ciberespacio.

\section{REFERENCIAS BIBLIOGRÁFICAS}

Burbules, C. (2001) Educación: riesgos y promesas de las nuevas tecnologias de la información. Buenos Aires, Granica.

Burbules, C. (2012) El aprendizaje ubicuo y el futuro de la enseñanza. Encuentros sobre Educación, 13, 3-14.

Caro Samada, C.; ArIso, J. M. ${ }^{a}$ y Plaza, J. (2014) La adicción a Internet y la terapia familiar sistémica como propuesta para favorecer un buen uso de la red. En Atas Digitais do

33. "La falta de confianza en el entorno digital está obstaculizando gravemente el desarrollo de la economía en línea europea"; y "los europeos no adoptarán una tecnología en la que no confíen; la era digital no es ni el gran hermano ni el salvaje oeste [...] los usuarios tienen que estar seguros y protegidos cuando se conecten en línea". Una Agenda digital para Europa, pp. 13 y 18. 
III Congresso Internacional das TIC na educação. Lisboa, Instituto de Educação da Universidade de Lisboa, 752-758.

Fraillon, J. et al. (2014) Preparing for Life in a Digital Age. The IEA International Computer and Information Literacy Study International Report. London, Springer.

Fernández Guerra, F. (2014) @Policia: las historias de un éxito. Madrid, Aguilar.

Fuentes, J. L. (2009) La interacción educador-educando en las nuevas modalidades educativas. Revista Electrónica del ADA Madrid, Relada, 3 (2), 127-134.

García ARetio, L. (2014) Bases, mediaciones y futuro de la educación a distancia en la sociedad digital. Madrid, Síntesis.

GARCía-GutiérREZ, J. (2013) Aproximación ética a la competencia digital. Los niveles de uso y sentido en ámbitos educativos virtuales. Revista Electrónica de Teoría de la Educación. Educación y Cultura en la Sociedad de la Información, 14 (3), 121-145.

Gil CANTERo, F. y Reyero GarCía, D. (2014) La prioridad de la filosofía de la educación sobre las disciplinas empíricas en la investigación educativa. Revista Española de Pedagogía, 258, 263-280.

INSAFE-INHOPE (2015) Working yogether for a better Internet for children and Young people. Annual report. Consultado el 10 de enero de 2015. http://www.saferinternet.org/c/document_library/get_file?uuid=0f285af4-8fff-489d-8da8-2298a8ed898d\&groupId=10137.

LIVINGSTONE, S. et al. (2014) Children's online risks and opportunities: Comparative findings from EU Kids Online and Net Children Go Mobile. Consultado el 10 de enero de 2015 http://eprints.lse.ac.uk/60513/.

Livingston, S.; HAdDON, S. et al. (2011) EU Kids online: final report. EU Kids on line. Consultado el 10 de enero de 2015. http://eprints.lse.ac.uk/39351/.

Martínez Otero, J. M. ${ }^{a}$ (2012) La protección de los menores en la política audiovisual de la Unión Europea: un objetivo prioritario. Revista de Derecho Político, 84, 497-528. http://dx.doi.org/10.5944/rdp.84.2012.9211

Mascheroni, G. y Cuman, A. (2014) Net Children Go Mobile Final Report. Consultado el 10 de enero de 2015. http://www.netchildrengomobile.eu/wp-content/uploads/2013/07/ NCGM_FinalReport_Country_DEF.pdf.

Moral Pérez, M. ${ }^{a}$ E. (1998) Protección jurídica de la infancia ante los medios de comunicación. Comunicar, 10, 198-206.

Muñoz Saldaña, M. y Mora-Figueroa Monfort, B. (2007) La corregulación: nuevos compromisos y nuevos métodos para la protección del menor de los contenidos televisivos. El caso holandés, en VV. AA. La ética y el derecho de la información en los tiempos del postperiodismo. Valencia, Fundación Coso, 421-438.

Pérez Alonso-Geta, M. ${ }^{a}$ P. (2008) Protección de la infancia y nuevas tecnologías de la comunicación: el Código PEGI de regulación de los videojuegos y juegos online. Revista Electrónica de Teoría de la Educación. Educación y Cultura en la Sociedad de la Información, 9 (3), 29-47.

Prats, E. y Graell, M. (2015) Autonomía y responsabilidad en el contexto de la sociedad de la información y las tecnologías, en Buxarrais, M. R. y Martinez, M. (coords.) Retos educativos para el siglo XXI. Autonomía, responsabilidad, neurociencia y aprendizaje. Barcelona, Octaedro, 91-100.

Ramiro VÁzQuez, J. (2013) Virtualizando infancias. Del niño competente al menor en riesgo a través de Internet, en Pérez Álvarez, S.; Burguera Amenave, L. y Paul Larrañada, K. (eds.) Menores e Internet. Madrid, Aranzadi, 31-55. 
Reyero García, D.; García Aretio, l. y Hernández Serrano, M. ${ }^{a}$ J. (2011) Autonomía y responsabilidad en el contexto de la sociedad de las tecnologías de la información y la comunicación. Consultado el 10 de enero de 2015. http://pendientedemigracion.ucm. es/info/site/docu/30site/ponencia4.pdf.

Salamanca Aguado, E. (2014) Respect for privacy and personal data protection in the context of mass surveillance of communication. Journal of the Spanish Institute for Strategic Studies, 4, 1-24.

SÁnchez Díez, A.; Llorca Díez, M. ${ }^{a}$ A. y Bueno Carrera, G. M. ${ }^{a}$ (2013) La utópica protección del código Pegr. Estudios sobre el Mensaje Periodístico, 19 (2), 711-723.

Weimann, G. (2014) New Terrorism and New Media. Washington, DC, Commons Lab of the Woodrow Wilson International Center for Scholars. Consultado el 10 de enero de 2015. http://www.wilsoncenter.org/publication/newterrorism-and-new-media. 